\title{
El ámbito subjetivo de aplicación del Régimen de Incompatibilidades del personal al servicio de las Fundaciones
}

\author{
Manuel Mesa Vila
}

Abogado consultor de fundaciones del sector público

\section{INTRODUCGIÓN}

La reforma legal introducida por la Disposición Final Tercera de la Ley 7/2007, de 12 de abril, del Estatuto Básico del Empleado Público, mediante la cual se amplía el ámbito de aplicación de la Ley 53/1984, de Incompatibilidades del Personal al Servicio de las Administraciones Públicas, al personal al servicio de entidades, corporaciones de derecho público, fundaciones y consorcios cuyos presupuestos se doten ordinariamente en más de un 50 por cien con subvenciones u otros ingresos procedentes de las Administraciones Públicas (artículo 2.1.g.), ha supuesto una importante novedad en el régimen jurídico y la gestión de los recursos humanos de determinadas fundaciones al incluir a su personal en el régimen general de incompatibilidades.

Lo mismo cabría decir de los máximos cargos ejecutivos de dichas fundaciones, que la Ley 3/2005, de incompatibilidades de altos cargos de la Administración de la Junta de Andalucía y su reglamento de desarrollo, el Decreto 176/2005, incluye dentro del régimen de incompatibilidades, los Presidentes, Directores y quienes ejerzan la función ejecutiva de máximo nivel de las demás entidades de la Administración de la Junta de Andalucía, y de las fundaciones y consorcios con participación directa de la misma superior al cincuenta por ciento, tanto si son nombrados por el Consejo de Gobierno como si son nombrados por los propios órganos de gobierno de las mismas.

Ambos regímenes difieren en las consecuencias jurídicas pero también, y esto es lo que más puede sorprender, en el criterio utilizado para la delimitación del ámbito de aplicación a las fundaciones: dotación presupuestaria ordinaria, en el caso del personal en general, y participación directa, para quienes ejerzan la función ejecutiva de máximo nivel. Se trata de criterios que delimitan realidades 
completamente diferentes, que pueden dar pie a la confusión y que, inevitablemente, se traduce en inseguridad jurídica y dificultades añadidas de gestión.

La utilización de conceptos jurídicos indeterminados amplía los márgenes de interpretación y resulta poco práctico. En el presente artículo pretendemos traducir esos conceptos y delimitar criterios objetivos, basándonos para ello en antecedentes normativos y en la aplicación de soluciones analógicas, que permitan delimitar claramente cuando debemos entender que una fundación queda sometida al régimen de incompatibilidades y cuando no.

\section{RÉGIMEN DE INCOMPATIBILDADES DEL PERSONAL}

La inclusión expresa del personal al servicio de las fundaciones en el ámbito del régimen de incompatibilidades, como hemos indicado, es un aportación de la Ley 7/2007, de 12 de abril, del Estatuto Básico del Empleado Público. El texto original de la Ley 53/1984 ni siquiera mencionaba a este tipo de entidades, en todo caso, podría hablarse de una interpretación analógica del original artículo 2.1.h. que incluía dentro del ámbito de aplicación al personal que preste servicios en empresas en que la participación del capital, directa o indirectamente, de las Administraciones Públicas sea superior al 50 por 100.

Hay que recordar que la incorporación expresamente recogida por ley de las fundaciones como entidades instrumentales de la Administración Pública es relativamente reciente y el peso específico que en la actualidad tienen no se podía ni imaginar a mediados de los ochenta cuando se publica el texto original de esta ley.

La Disposición Final Tercera de la Ley 7/2007, modifica el ámbito de aplicación de la ley de incompatibilidades incluyendo el apartado 2.1.g. en virtud del cual se encuentra dentro de su ámbito el personal al servicio de entidades, corporaciones de derecho público, fundaciones y consorcios cuyos presupuestos se doten ordinariamente en más de un 50 por cien con subvenciones u otros ingresos procedentes de las Administraciones Públicas.

El precepto descrito, al igual que la práctica totalidad del contenido de la ley, se considera bases del régimen estatutario de la función pública, dictadas al amparo del artículo 149.1,18, de la Constitución.

El Real Decreto 598/1985, que desarrolla la Ley 53/1984, ha de entenderse también afectado por esta reforma, ya que su ámbito de aplicación se remite de manera expresa a la ley. 
En el ámbito de la Comunidad Autónoma de Andalucía, la primera norma de desarrollo que se dictó fue el Decreto 8/1985, que definía un ámbito de aplicación genérico del régimen de incompatibilidades establecido por la norma estatal al personal al servicio de la Administración de la Junta de Andalucía y de los Organismos de ella dependientes, cualquiera que sea la naturaleza jurídica de la relación de empleo.

El reciente Decreto 524/2008, de 16 de diciembre, (BOJA núm. 6 de 12 de enero) por el que se regulan las competencias y el procedimiento en materia de incompatibilidades del personal al servicio de la Administración de la Junta de Andalucía y del Sector Público Andaluz, reproduce prácticamente el ámbito de aplicación de la nueva redacción del artículo 2 de la ley estatal y considera incluido al personal de los consorcios y fundaciones cuyos presupuestos se doten ordinariamente en más de un 50 por 100 con subvenciones u otros ingresos procedentes de la Administración de la Junta de Andalucía o de sus agencias y demás entidades de Derecho Público.

Así pues, en el ámbito de las fundaciones queda claro que el requisito y elemento constitutivo de la situación jurídica de sometimiento al régimen de incompatibilidades del personal es el hecho de que la entidad se dote ordinariamente en más de un $50 \%$ de subvenciones u otros ingresos procedentes de la Administración de la Junta de Andalucía.

Resulta significativo que no se haya hecho una referencia más concreta y precisa y el decreto no incluya, para establecer su ámbito de aplicación, el concepto de fundaciones del sector público, perfectamente definido y delimitado en la Ley 9/2007, de 22 de octubre, de la Administración de la Junta de Andalucía, como sí hace por el contrario al referirse a las sociedades mercantiles del sector público andaluz. Ambos tipos de entidades instrumentales encuentran un tratamiento muy similar en la citada ley, por lo que no se entiende muy bien por qué en un caso sí se refiere al término jurídico preciso, caso de las sociedades, y sin embargo se aparta de ese criterio, incluyendo un concepto jurídico nuevo e indeterminado, cuando se refiere a las fundaciones.

Se trata, por tanto, de buscar elementos definitivos que permitan diferenciar cuando el personal de una fundación se encuentra sometido a régimen de incompatibilidades, para lo que el decreto no se sabe de antemano si ha ampliado o ha reducido el ámbito de aplicación al no referirse inequívocamente a las fundaciones del sector público como hubiera sido deseable.

El Decreto exige que en las fundaciones concurran dos elementos: 
1. Que se dote en más de un $50 \%$ de subvenciones u otros ingresos procedentes de la Junta de Andalucía.

2. Que esa dotación se produzca ordinariamente.

Las fundaciones que reúnen los requisitos para ser consideradas pertenecientes a la categoría de "fundaciones del sector público andaluz", se pueden considerar, por su propia naturaleza jurídica, incluidas en el ámbito de aplicación del Decreto. Para ser consideradas como entes instrumentales de la Junta, las fundaciones han de cumplir con las circunstancias previstas en el artículo 55.1 de la Ley 10/2005, de Fundaciones que considera fundaciones del sector público andaluz:

- Aquellas que se constituyan con una aportación mayoritaria, directa o indirecta, de la Administración de la Junta de Andalucía, sus organismos públicos o demás entidades o empresas de la Junta de Andalucía,

- Aquellas que su patrimonio fundacional, con un carácter de permanencia, esté formado en más de un cincuenta por ciento por bienes o derechos aportados o cedidos por dichas entidades.

- Aquellas en las que la Administración de la Junta de Andalucía tenga una representación mayoritaria. Se entenderá que existe ésta cuando más de la mitad de los miembros de los órganos de administración, dirección o vigilancia de la fundación sean nombrados por la Junta de Andalucía, a través de cualquiera de sus instituciones, entidades, órganos, organismos autónomos o empresas.

Como vemos, la financiación mayoritaria no es uno de los elementos determinantes para incluir a las fundaciones dentro de la categoría de fundaciones del sector público andaluz. Pero no siendo un elemento determinante en el momento de su constitución, sí es una característica fundamental en su funcionamiento y podemos afirmar que por su propia naturaleza jurídica, por la finalidad para la que se crean y su carácter instrumental respecto de la Junta de Andalucía, las fundaciones del sector público andaluz, tienen como sistema de financiación característico la dotación económica estable desde los presupuestos de la Junta de Andalucía, mediante subvenciones en unos casos y mediante sistema PAIF en otros.

Por lo tanto, podemos afirmar que el personal al servicio las fundaciones del sector público andaluz se encuentra incluido en el ámbito de aplicación del Decreto 524/2008. 
Pero la expresión utilizada como criterio delimitador es mucho más amplia "fundaciones cuyos presupuestos se doten ordinariamente en más de un 50 por 100 con subvenciones $u$ otros ingresos procedentes de la Administración de la Junta de Andalucía o de sus agencias y demás entidades de Derecho Público" y con ello puede afectar a otras fundaciones que, no alcanzando la categoría legal de fundaciones del sector público andaluz, se financien mayoritariamente a través de subvenciones. Para estos casos, el Decreto utiliza el adverbio modal "ordinariamente". Este es el auténtico concepto jurídico indeterminado que puede resultar clave a la hora de determinar si una determinada fundación se encuentra dentro del ámbito subjetivo del Decreto.

El Diccionario de la Real Academia Española de la Lengua define el adverbio "ordinariamente" como "frecuentemente, regularmente, por lo común", por lo tanto en principio, no cabría exigir más que la situación de financiación mayoritaria se produzca una serie de ejercicios consecutivos para entender que estamos ante una situación de regularidad.

No obstante, si observamos el contexto en el que se encuentra la expresión, debemos matizarla jurídicamente, las consecuencias prácticas para el personal son muy relevantes. Hemos de entender que estamos intentando resolver sobre un régimen jurídico especial aplicable al personal que exige un cierto carácter estructural y que no pude responder a una mera coyuntura de uno o varios ejercicios concretos, exige en definitiva estabilidad, por lo que nos hace pensar en que el ejecutivo a la hora de redactar el reglamento ha tenido en el punto de mira a aquellas fundaciones concebidas con la vocación de dotarse regularmente con fondos procedentes de la Junta de Andalucía, esas fundaciones no son otras que las fundaciones instrumentales o fundaciones del sector público andaluz.

Obsérvese que la Ley 30/2007 de Contratos del Sector Público también utiliza el criterio de la financiación mayoritaria de su actividad por parte de otros entes que deban ser considerados como poderes adjudicadores (artículo 3.3.b) para delimitar las entidades que deben ser considerados poderes adjudicadores. En ese caso la Junta Consultiva de Contratación Administrativa de la Consejería de Economía y Hacienda ha dictaminado (Dictamen 18/2008) que la calificación de poder adjudicador de un organismo debe efectuarse sobre una base anual y el periodo que debe considerarse más adecuado para calcular el modo de financiación de dicho organismo es el ejercicio presupuestario en el que se inicia el procedimiento de adjudicación de un contrato determinado tomando como base las cifras disponibles al inicio del ejercicio presupuestario, aunque tengan el carácter de previsiones. Con esta afirmación el órgano consultivo está dando carácter coyuntural a la categoría de po- 
der adjudicador, es decir, una entidad puede ser poder adjudicador un año y al año siguiente puede dejar de serlo o viceversa y alternando tantas cuantas veces varíen sus circunstancias económicas.

No es posible extrapolar esta afirmación a nuestro ámbito, no se dan las circunstancias para hacer una aplicación analógica de este dictamen. De momento hemos de apuntar que la legislación de contratos omite el importante matiz de tiempo "ordinariamente".

El sometimiento del personal al régimen de incompatibilidades exige por su propia naturaleza una cierta estabilidad en la consideración jurídica de la fundación de que se trate y entendemos que esa consideración y esa financiación ordinariamente pública debe haberse producido durante los últimos ejercicios, la mayoría de los ejercicios de vida de la fundación y debe exigirse también un componente predictivo ya que debe preverse que esa situación de financiación mayoritaria se va a seguir produciendo en los próximos años.

Con esta afirmación hacemos una interpretación muy amplia y tal vez algo generosa del adverbio "ordinariamente", que paradójicamente restringe el ámbito de aplicación de la norma, pero consideramos que se ajusta más a las consecuencias jurídicas y al contexto en el que nos estamos moviendo.

Por último, una interpretación teleológica nos lleva a observar que el principio que el Decreto pretende salvaguardar es el principio fundamental de la dedicación del personal a un solo puesto o actividad pública, salvo las excepciones establecidas, consagrado por la Ley 53/1984, desde un punto de vista estricto solo las fundaciones del sector público están diseñadas y concebidas desde su origen para realizar parcelas de actividad pública que le sean encomendadas.

Si la fundación objeto de análisis participa en las características que hemos descrito en los párrafos anteriores, la consecuencia será que su personal está sometido a régimen de incompatibilidad y, por tanto, el ejercicio de una segunda actividad pública o privada requerirá, con carácter previo a su inicio, preceptiva autorización o reconocimiento de compatibilidad por el órgano competente, salvo las actividades exceptuadas del régimen de incompatibilidades en el artículo 19 de la Ley 53/1984.

La autorización, reconocimiento o denegación de la compatibilidad genérica o de la específica, corresponde a la persona titular de la Consejería de Justicia y Administración Pública. La instrucción de los procedimientos, por su 
parte, corresponde a la Inspección General de Servicios de la Junta de Andalucía. Los órganos responsables de la gestión de personal de las entidades o centros en que la persona interesada desempeñe su primer puesto o actividad, deben facilitar la tramitación a la persona solicitante de la autorización o reconocimiento de compatibilidad.

\section{RÉGIMEN DE INCOMPATIBILIDADES DE ALTOS CARGOS}

El régimen de incompatibilidades de altos cargos se encuentra regulado en la Ley 3/2005, de incompatibilidades de altos cargos de la Administración de la Junta de Andalucía y de declaración de actividades, bienes e intereses de altos cargos y otros cargos públicos y su norma de desarrollo, el Decreto 176/2005, de 19 de julio.

El artículo 2 de la ley, considera altos cargos de la Junta de Andalucía y, por tanto, dentro de su ámbito de aplicación, entre otros a:

h) Los Presidentes, Directores y quienes ejerzan la función ejecutiva de máximo nivel de las demás entidades de la Administración de la Junta de Andalucía, y de las fundaciones y consorcios con participación directa de la misma superior al cincuenta por ciento, tanto si son nombrados por el Consejo de Gobierno como si son nombrados por los propios órganos de gobierno de las mismas.

Una vez más el ordenamiento jurídico se separa del concepto general de fundación del sector público andaluz consagrado por la Ley 9/2007. No obstante, en esta ocasión podría contar con la disculpa de tratarse de una ley anterior en el tiempo, si bien podemos decir que en la fecha de elaboración y aprobación de la ley (marzo - abril de 2005) el concepto de fundación del sector público ya se venía manejando con fuerza, por ejemplo en la Ley 10/2005 de Fundaciones, que es coetánea a la que estamos analizando, o en el ámbito del Estado en la Ley 50/2002.

Si, como hemos dicho, podríamos disculpar la separación del concepto genérico de fundación del sector público, consideramos inapropiado utilizar un criterio diferente al que utiliza el Decreto 524/2008 para el resto del personal. La finalidad perseguida y las consecuencias jurídicas son diferentes: en un caso, el Decreto pretende garantizar la plena dedicación y la imparcialidad en el ejercicio de sus funciones por parte de los trabajadores; en el segundo, la Ley pretende reforzar la independencia, la imparcialidad y la dedicación exclusiva a los asuntos públicos de los altos cargos, evitando cualquier interfe- 
rencia en los intereses públicos de otros intereses y además la regulación de medidas encaminadas a aumentar la transparencia en la actividad pública. A pesar de ese pequeño matiz diferencial no se entiende muy bien que se hayan incluido elementos de delimitación del ámbito subjetivo de aplicación diferentes.

En este caso, como hemos dicho se vuelve a huir del concepto de fundación del sector público andaluz, y en esta ocasión se utiliza el elemento de la participación en más de un 50\%. Se utiliza el mismo criterio que el apartado e del artículo 2 utiliza para las sociedades mercantiles: la participación, un concepto muy consolidado en derecho mercantil, pero cuya extensión al ámbito de las fundaciones precisa ser matizado.

La participación en una fundación se puede hacer por una doble vía:

- La participación como fundador realizando una aportación al fondo fundacional.

- La participación en el órgano de gobierno de la fundación, que no es otro que el Patronato.

En ambos casos si esa aportación o esa participación en el patronato resultase superior al $50 \%$ estaríamos hablando de una fundación cuyo máximo cargo ejecutivo se encontraría sometido al régimen de incompatibilidades.

Esta forma de definir las fundaciones incluidas en el ámbito subjetivo de la ley toma elementos de la definición de fundación del sector público del artículo 55 de la Ley 10/2005, pero con un matiz importante, mientras que en aquélla la participación en órganos de gobierno o la aportación al fondo fundacional puede ser indirecta, es decir, a través de otras entidades u organismo de la propia Junta de Andalucía, aquí se exige que la participación sea directa.

Son matices y consideraciones que tienen una enorme trascendencia práctica y que sólo llevan a la confusión. Lo que sí resulta manifiestamente mejorable es, como ya hemos indicado, el hecho que no coincidan los criterios para el personal común y para los altos cargos. Con este panorama podemos perfectamente encontrarnos con fundaciones en que el personal esté sometido a régimen de incompatibilidades y el director no y viceversa, por la concurrencia de unos pequeños matices. 


\section{CONCLUSIÓN}

De lege ferenda sería deseable utilizar en lo sucesivo el concepto que el propio ordenamiento jurídico andaluz ha creado, nos referimos al concepto de fundación del sector público andaluz que si bien su definición legal deja mucho que desear por el amplio margen de interpretación que deja, sería recomendable su utilización de cara a delimitar el régimen jurídico aplicable a su personal y a otros muchos asuntos de capital importancia para su gestión en los que tampoco se utiliza el término preciso.

Manuel Mesa Vila

Abril 2009 